\title{
OVERLOAD CONFUSION, STRESS AND COPING IN A RETAIL SETTING
}

Marion Brandstaetter, Karl-Franzens-University Graz, Austria Thomas Foscht, Karl-Franzens-University Graz, Austria

\begin{abstract}
Today's consumers are often faced with an overchoice situation that can result in dysfunctional consequences for the consumer, e.g. (overload) confusion or stress. Although previous research has discussed negative emotions and potential confusion reduction strategies theoretically, the concept of overload confusion has not been linked to stress and coping theory. Therefore, this study investigates if overload confusion evokes feelings of stress in terms of threat and challenge emotions and which coping strategies consumers employ in the context of grocery shopping. The results show that threatened consumers use emotion-focused coping strategies more often, whereas challenged consumers predominantly engage in problem-focused coping.
\end{abstract}

References available upon request 